\title{
DEZ PRINCÍPIOS PARA AVALIAR A USABILIDADE DA INTERFACE HUMANO COMPUTADOR DE AMBIENTES VIRTUAIS DE APRENDIZAGEM (AVA)
}

\author{
Gildásio Guedes Fernandes ${ }^{1}$
}

\section{INTRODUÇÃO}

O termo usabilidade se origina na ciência cognitiva e significa fácil de usar. A definição da norma da International Organization for Standardization (ISO, № 924111), Guidance on usability (1998), diz que usabilidade é a capacidade de um produto ser utilizado por indivíduos em busca de atingir objetivos específicos com eficácia, eficiência e satisfação Nos primórdios do decênio de 1980, passa a integrar as áreas de psicologia e ergonomia. A este respeito, Nielsen (1993) apresenta cinco características que podem identificar uma interface que contém usabilidade, quais sejam: facilidade de aprendizagem, eficiência de uso, facilidade de memorização, baixas taxas de erro e satisfação subjetiva.

No decorrer dos processos de ensino e aprendizagem on-line através de ambientes virtuais de aprendizagem um dos fatores importantes para o sucesso desses processos é a qualidade da interface computacional. Se um ambiente oferece aos seus usuários uma interface obedecendo aos principais atributos de usabilidade, as atividades podem ser realizadas de forma menos cansativas e mais agradáveis

Para averiguar ${ }^{2}$ a usabilidade na interface dos ambientes virtuais de aprendizagem Moodle, e-Proinfo e Solar foi aplicado um cheklist contendo 30 itens distribuídos em 06 critérios comuns aos grupos de avaliadores, formados por profissionais da área de informática e por um grupo de educadores de outras áreas. Os profissionais de informática são desenvolvedores de sistemas, quatro dos quais vinculados à UFC e os demais à UFPI. Os educadores são vinculados a UFPI.

Esse cheklist foi construído baseado nas recomendações de usabilidade constantes em Bastian \& Scapin (1995), Shneiderman (1998), Nielsen (2000), Silva (2000) e Guedes(2008). Os 6 (seis) critérios dessa avaliação estão delineados de

\footnotetext{
${ }^{1}$ Doutor em Educação. Diretor do Centro de Educação Aberta e a Distância (CEAD), da Universidade Federal do Piauí. Email: guedes@ufpi.edu.br

${ }^{2}$ Este artigo possui sua versão original publicada na obra FRANÇA-CARVALHO, A. D. Conversas pedagógicas: reflexões sobre o cotidiano da docência. Teresina, EDUFPI, 2010.
} 
acordo com o enfoque em usabilidade: 1 - Apresentação Geral da Interface; 2 Navegabilidade; 3 - Legibilidade da Interface; 4 - Mecanismos de Comunicação do Ambiente; 5 - Meios de Publicação de Conteúdos e 6 - Documentação On-line do Sistema

Em cada momento da avaliação é atribuído um conceito, segundo os critérios representados pelo entendimento dos avaliadores, variando em: Excelente $(E)$; Muito Bom (MB); Bom (BM) regular (R); Insuficiente (I), convertidos, posteriormente, em conceitos numéricos (respectivamente, $4 ; 3 ; 2 ; 1$ e 0 ), com o intuito de calcular a média ponderada e o percentual obtidos através dos escores atribuídos a cada item avaliado.

A Tabela 1 e a Tabela 2 explicitam de forma mais adequada os percentuais obtidos das situações descritas nos parágrafos anteriores.

Tabela 1 - Resultados da avaliação aplicada aos profissionais de informática.

\begin{tabular}{l|c|c|l}
\hline \multicolumn{1}{c|}{ Títulos dos critérios avaliados } & Moodle & e-Prolnfo & Solar \\
\hline Apresentação geral da interface & 80.4 & 53.1 & 82.8 \\
\hline Legibilidade da interface & 68.1 & 43.1 & 84.3 \\
\hline Navegabilidade da plataforma & 80.2 & 56.2 & 90.6 \\
\hline Mecanismos de comunicação & 76.2 & 46.8 & 70 \\
\hline Meios para publicação de conteúdos & 70 & 34.3 & 82.5 \\
\hline Documentação on-line do ambiente & 76.5 & 47 & 37 \\
\hline
\end{tabular}

Fonte: Autor, 2010.

Tabela 2 - Resultados da avaliação aplicada aos profissionais Educadores.

\begin{tabular}{l|c|c|c}
\hline \multicolumn{1}{c|}{ Títulos dos critérios avaliados } & Moodle & e-Prolnfo & Solar \\
\hline Apresentação geral da interface & 85 & 59 & 74 \\
\hline Legibilidade da interface & 83 & 78.8 & 94 \\
\hline Navegabilidade da plataforma & 86.1 & 67.9 & 79.6 \\
\hline Mecanismos de comunicação & 88.8 & 84.6 & 92.6 \\
\hline Meios para publicação de conteúdos & 71.6 & 76.9 & 77.7 \\
\hline Documentação on-line do sistema & 86.6 & 81.5 & 57.7 \\
\hline
\end{tabular}

Fonte: Autor, 2010. 


\section{ANÁLISE DOS DADOS DA PESQUISA}

\subsection{Avaliação geral da interface}

O critério avaliação geral da interface assim como os demais é composto de cinco itens. Aqui, os aspectos tratados aludem às cores, à orientação ao usuário, ao formato do design; à adequação ao tipo de fontes utilizadas na interface, a hierarquia na disposição dos conteúdos relacionados, a proximidade entre as partes explicitas ao contraste de fundo, figuras e letras, ou seja, o design da interface como um todo, como mostra o Gráfico 1.

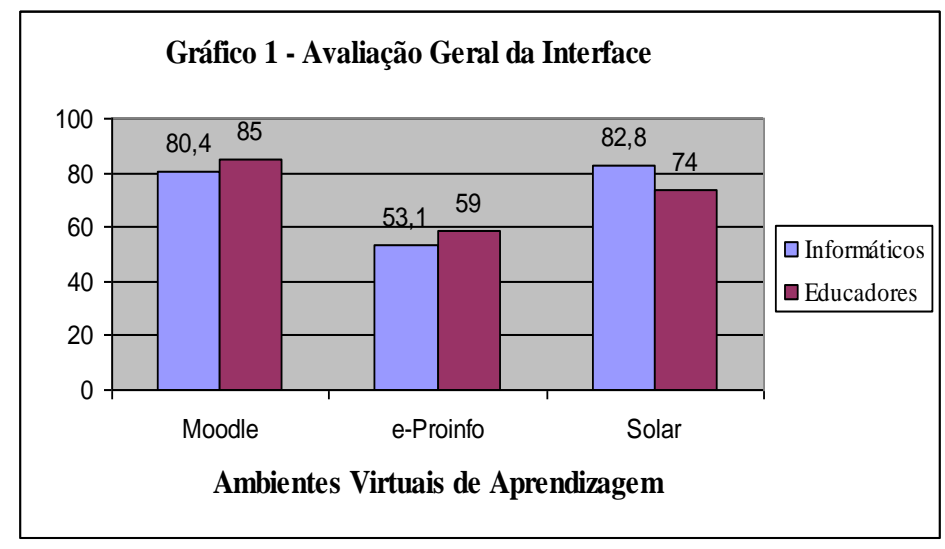

Fonte: Dados da pesquisa, 2010.

Nesse critério, avaliação geral da interface, o Moodle consegue avaliação mais positiva do que o Solar e bem melhor do que o e-Prolnfo, quando avaliados pelo grupo de educadores, por outro lado o Solar é melhor avaliado pelo grupo de informáticos.

Quanto ao e-proinfo avaliação é próxima uma da outra tanto por informáticos quanto pelos educadores conforme o Gráfico 1. O que observamos é que há uma ligeira inversão na avaliação do Moodle e do Solar pelos dois grupos de avaliadores. Isto ocorre porque o Moodle oferece orientação mais adequada ao usuário, proporcionando-lhe chance de ele mesmo responder algumas das perguntas que, em geral, são feitas em ambientes dessa natureza, quais sejam, as mencionadas: Onde estive? Onde estou? Para onde vou? Ademais, o solar, por sua vez, apresenta design mais adequado para o usuário, com tamanho de letra maior do que a dos demais ambientes e uma quantidade de menus mais reduzida. Quanto ao e-proinfo esse apresenta menus na horizontal que confunde o usuário, pois os sub-menus 
sobrepõem determinados menus lá existentes, além disso as cores apresentadas nesse ambiente e-proinfo,são de tonalidades muito forte o que de alguma forma, ocasiona cansaço ao usuário e aumenta o tempo de leitura.

\subsection{Navegabilidade da plataforma}

A navegabilidade da plataforma enfoca a padronização do ambiente e as alternativas para os indivíduos mais experientes. A quantidade de click para a realização de uma tarefa, a relação entre as páginas internas e a página principal do ambiente e a facilidade para identificar um determinado curso. Conforme o Gráfico 2, registramos um bom percentual, sendo superior do Solar (90.6) no grupo de informáticos seguido pelo Moodle (80,2\%). No grupo de educadores, observou-se superioridade para o moodle (86.1) seguido pelo solar (80.2), novamente uma inversão no percentual desse grupo de avaliadores para esses dois ambientes. Em oposição a essa boa avaliação, indentifica-se o baixo percentual obtido pelo $e$ Prolnfo (56,2\%) no grupo de educadores, e (67.9\%) avaliado pelos informáticos. Decerto, isto advém do fato de o Solar apresentar, em quase todas as telas, um vínculo entre as funções e de exigir quantidade menor de clicks para conclusão de uma tarefa.

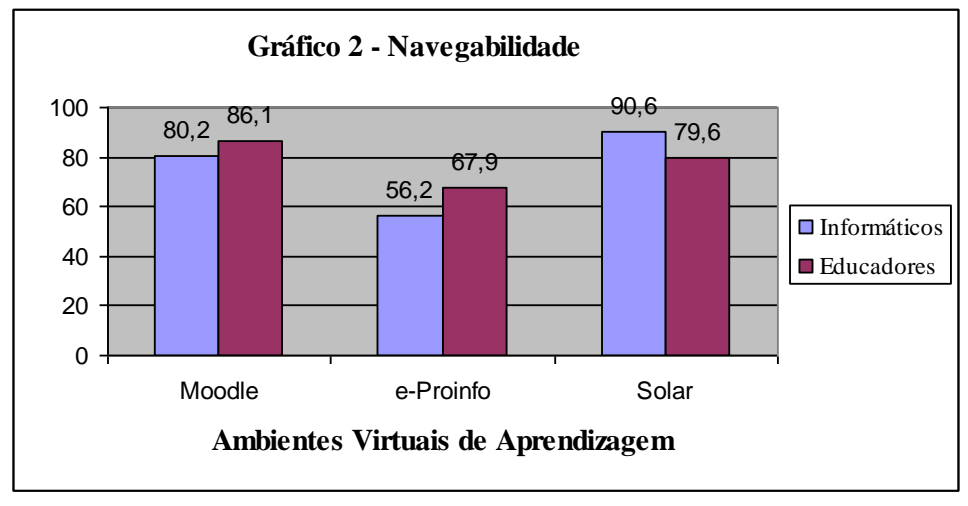

Fonte: Dados da pesquisa, 2010.

Ademais, o ambiente e-Prolnfo se desmembra em três ambientes principais, identificadas tanto por suas funções específicas, como pelas cores dos respectivos menus. Sendo eles: ambiente administrativo (ou ambiente vermelho); ambiente do curso (ou ambiente azul); ambiente da turma (ou ambiente amarelo). Em cada um desses ambientes os menus desempenham funções semelhantes, com diferença 
maior entre o ambiente administrativo e os restantes. Isto gera certa inquietação no caso de os usuários utilizarem perfis diferentes.

\subsection{Legibilidade da plataforma}

O próximo critério avaliado destina-se à legibilidade da interface, explorando o tamanho da fonte, a clareza das expressões, o contraste, o alinhamento e a proximidade entre as partes que compõem os menus, bem como as facilidades para matrícula. O Solar, o Moodle e o e-Proinfo atingem bons percentuais no grupo de educadores, já o e-Proinfo no grupo de informáticos continua aquém, com 43,1\%, bem menor do que o percentual de $84,3 \%$ obtido pelo Solar, conforme Gráfico 3.

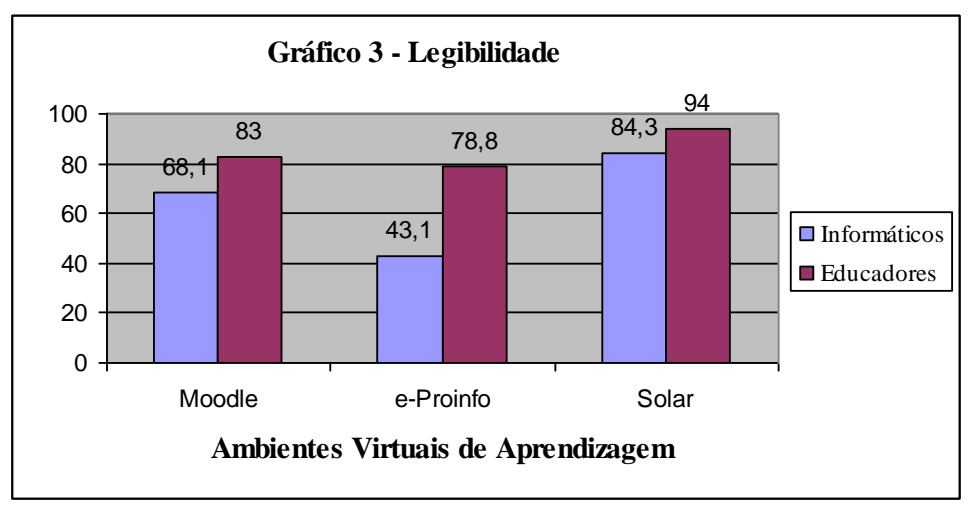

Fonte: Dados da pesquisa, 2010.

Nesse critério Legibilidade (Gráfico 3) a avaliação mantém-se convergente tanto no grupo de educadores quanto no grupo de informáticos, ou seja o solar foi melhor avaliado pelos dois grupos, não ocorrendo uma inversão tanto como no caso do atributo da avaliação geral da interface, quanto no atributo navegabilidade em que a avaliação foi divergente respectivamente no Gráfico 1 e no Gráfico 2.

A primazia do Solar pode ser explicada porque apresenta, em suas páginas, distribuição de links de melhor visibilidade e melhor compreensão, além de não trazer excessiva quantidade de informações, fator que compromete a leitura. A grande surpresa nesse atributo é a vantagem do e-proinfo sobre o Moodle quando avaliado pelos educadores. A outra surpresa é a boa avaliação dos três ambientes pelos educadores com 94\%, 83\% e78.8\% respectivamente Solar, Moodle e eProinfo.

\subsection{Mecanismos de comunicação}


Quanto aos mecanismos de comunicação, na avaliação dos informáticos, os ambientes Moodle, e-Prinfo e Solar conseguem porcentagem inferior isto é, 76,2\% 46.8, e 70\%, respectivamente, em relação à boa avaliação atribuída pelos educadores que é de 88.8, 84.6, 92.5. O menor índice é a avaliação do e-Proinfo, com meros $46,8 \%$, dada pelos informáticos (Gráfico 4).

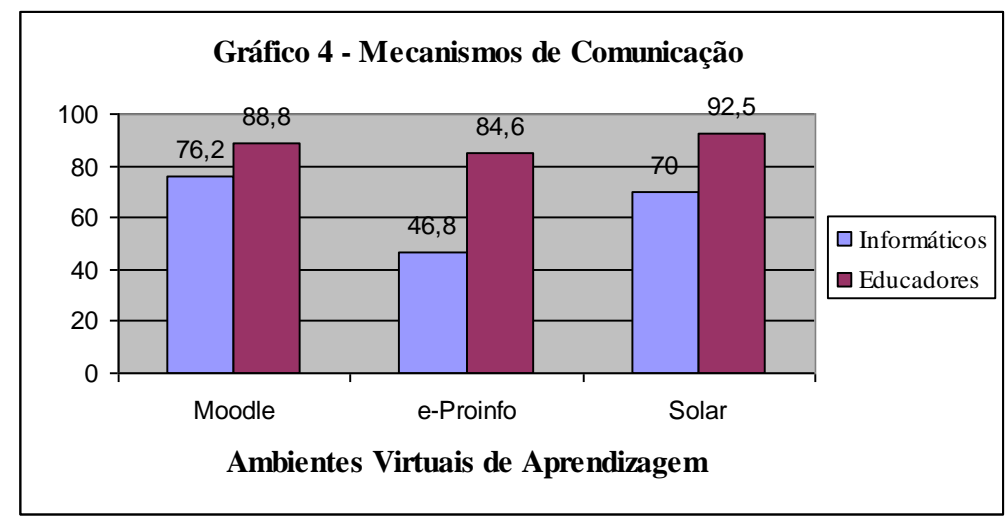

Fonte: Dados da pesquisa, 2010.

Embora o Solar consiga a melhor pontuação de 92.5 por parte dos educadores, o mesmo não acontece por parte dos informáticos, pois o Solar está abaixo, perdendo para o Moodle com 6.2\% (Gráfico 4), talvez por conta de apresentar melhor as respostas e os comentários dos fóruns, tal como discutido antes, onde o Moodle conquista o primeiro lugar no grupo de informáticos. São eles condizentes com os quesitos: hierarquia em que os conteúdos estão dispostos e a chance da página pessoal dos envolvidos nos processos de ensino e de aprendizagem ser compartilhada por todos. Isto nos permite afirmar que, no caso dos mecanismos de comunicação, a diferença é pequena entre Moodle e Solar, para os educadores, ainda que bastante acentuada em relação ao e-Proinfo para os informáticos.

Afora essas considerações, os resultados em termos de ordenação, diferem dos extraídos junto ao grupo de educadores, em que o Solar foi melhor que o Moodle e este por sua vez, melhor que o e-Prolnfo. O contrário ocorre com a avaliação dos informáticos, pois o Moodle foi mais bem avaliado que o Solar e este melhor que o e-Proinf.

\subsection{Meios disponíveis para publicação de conteúdos}


O próximo critério trata dos meios disponíveis para publicação de conteúdos. Seus itens correspondem às diversas formas e os meios de como os conteúdos são publicados pelos Ambientes Virtuais de aprendizagem (AVA). Os autores oferecem vários formatos de publicação, principalmente se aceitam os principais editores de textos, que os usuários conhecem; se incorporam imagens e fotografias, ou se admitem vídeos.

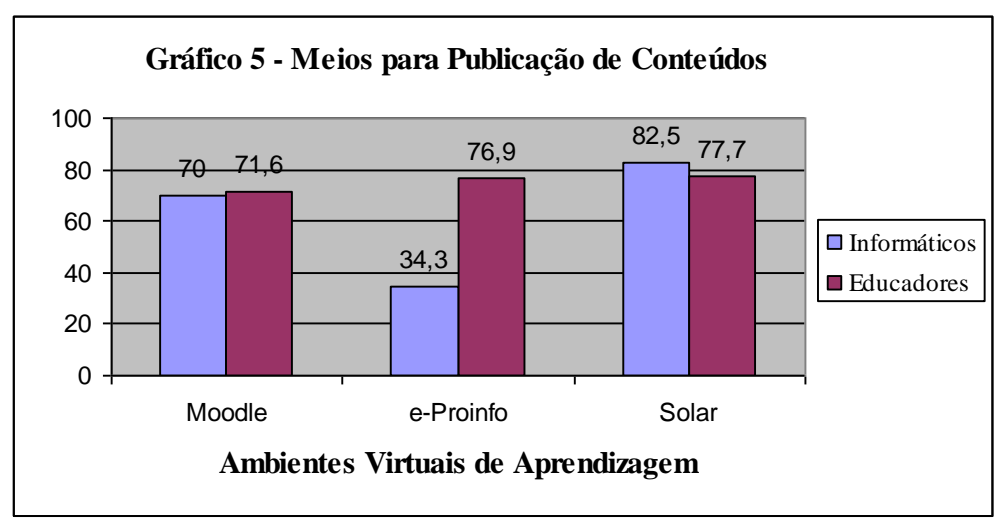

Fonte: Dados da pesquisa, 2010.

Nesse critério os três ambientes virtuais de aprendizagem, quando avaliados pelos educadores, alcançam escores próximos 71\%; 76,9\%; e $77,7 \%$, respectivamente, para o Moodle, e-Proinfo e Solar, conforme o Gráfico 5 acima. O mesmo não ocorre na avaliação dos ambiente pelo grupo de informáticos; neste caso a discrepância ocorre no baixo escore conseguido pelo e-Proinfo, qual seja: $34.3 \%$. O Solar foi o ambiente melhor avaliado pelos dois grupos $(82.5 \%)$ dado pelos informáticos e $77.7 \%$ atribuído pelos educadores. Todos os ambientes dispõem da maioria das mídias, sendo que a diferença está na forma de armazenamento. Em qualquer instância, não é muito fácil para um usuário sem experiência em informática colocar animação, figura ou gráfico nos AVAs avaliados.

\subsection{Documentação on-line do sistema}

O próximo critério alude à documentação on-line do sistema e versa sobre a ajuda on-line, se estão à disposição dos interessados, conforme mostra o Gráfico. Traz orientação e descrição das tarefas a serem cumpridas, passo a passo, 
mensagens de erro de fácil interpretação e documentação para consultas de cunho técnico.

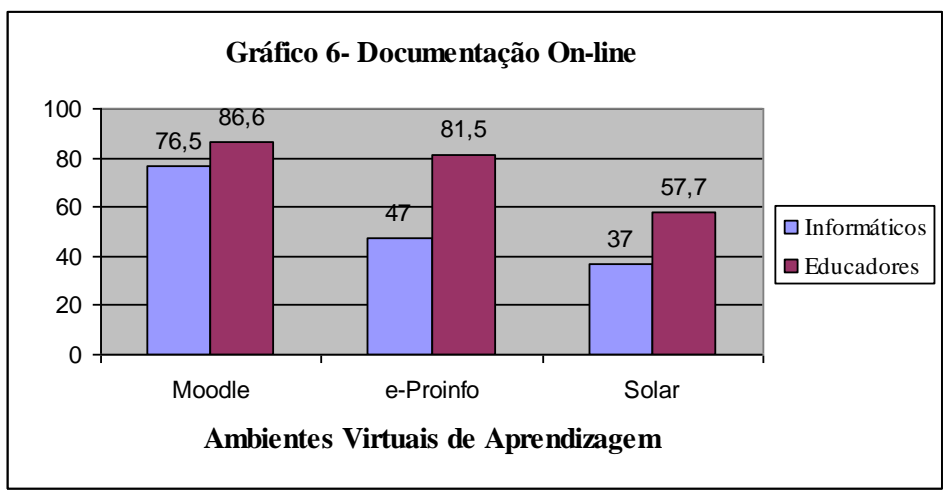

Fonte: Dados da pesquisa, 2010.

Em se tratando deste item, tanto o Moodle quanto o e-Proinfo estão mais bem avaliados pelo grupo de educadores, com escore máximo obtido das respostas afirmativas, de $86.6 \%$ e $82.5 \%$, respectivamente. Mas um fato pode ser notado na avaliação dos informatas, a saber: avaliação da documentação on-line quando solicitada ao AVA Moodle obtém um escore bem superior quando comparado com os demais, pois a nota é 76.5 , enquanto o e-Proinfo obteve $47 \%$ e o Solar apenas $37 \%$. Como o informata tem uma melhor percepção do que venha a ser uma boa documentação on-line está confirmada a tendência mundial da produção da documentação do Moodle. Dependendo da configuração adotada, o Moodle dispõe ainda de vasta documentação de ajuda on-line. Por ser um ambiente de código aberto desde a concepção inicial, apresenta bastante orientação, pois o ambiente é construído de forma colaborativa. A orientação está disponível com características próprias dos sistemas de computação free, com lista de discussão, manuais on-line, fóruns e home page.

No caso do e-Proinfo, mesmo com boa avaliação fornecida pelos educadores, não oferece manual on-line, o help do ambiente (ajuda on-line) é pouco informativo, e só há acesso ao menu ajuda, com a saída do ambiente e retorno à tela do login. Além desses três pontos negativos, o e-mail cadastrado no e-Proinfo exige bastante espaço de armazenamento e o Serviço de Atendimento ao Usuário (SAU) está disponível apenas para um tipo de usuário, o administrador de entidade. Em posição oposta, o Solar consta com 58\%, o que decorre do fato de não dispor de guia adequado on-line para o usuário, pois se reduz à tela inicial. 


\section{PRINCÍPIOS PARA AVALIAR A USABILIDADE DA INTERFACE DE AVA}

Por conta de tudo que analisamos, apresentamos dez princípios destinados ao desenvolvimento de interfaces de AVA, as quais se fundamentam nos dados coletados e, inevitavelmente, nas observações e na experiência empírica vivenciada durante o desenvolvimento do trabalho para aperfeiçoar o modelo proposto.

As heurísticas estão baseadas em diversos princípios que são necessários para a construção de uma interface amigável para um AVA, que propõe contemplar interação, colaboração, comunicação e funcionalidade adequadas ao usuário.

Heurísticas 1 - Alinhamento. O alinhamento é aplicado, principalmente, na produção de textos para a web, haja vista que qualquer material deve ter alinhamento entre os três mais utilizados na edição de textos - à esquerda, centralizado, à direita. Há quem recomende que os textos para a web não devem estar no modo justificado. Porém, discordamos, porque se trata de recomendação que contraria frontalmente a evolução histórica da leitura e do leitor: desde os primeiros anos de ensino fundamental, como mencionamos antes, a criança aprende a ler em livros e a maior parte deles (ou todos) adere ao alinhamento justificado.

De qualquer forma, é consensual que devemos selecionar determinada formatação e mantê-la em toda a peça, qualquer que seja a escolhida. Esse princípio dá aparência agradável porque uniformizado, embora nada impeça que, vez por outra, se recorra a um segundo, com a intenção de quebrar a monotonia do texto demasiadamente uniforme. Em qualquer instância, as escolhas, devem vir sempre acompanhadas de teste, até porque uma mesma peça pode ter visual aceitável num tipo de alinhamento e não ficar bem com outro.

Heurísticas 2 - Proximidade entre partes inter-relacionadas. Essa heurística refere-se ao relacionamento que as partes mantêm entre si, na tela. Dois ou mais itens colocados muito próximos, inevitavelmente, dão idéia de manter ligação, como se fizessem parte um do outro, proporcionando, então, noção de conjunto e de todo. Em outras palavras, elementos contíguos tendem a formar grupos percebidos como bloco único pelo público, fazendo com que cada elemento perca sua individualidade.

Por outro lado, pode ocorrer que um título fique longe do item a que se refere e mais perto de outro, com que não mantém relação ou esta é frágil. Neste sentido, revendo reforçamos a premissa de que títulos e subtítulos devem estar juntos o 
suficiente, de modo a permitir que os usuários notem, de imediato, a conexão existente.

Heurísticas 3 - Contraste. O contraste melhora a percepção de um objeto, incluindo a diferença entre ele e seu entorno. Acentua-se graças ao uso de cores, de iluminação, movimento, aparência, tamanho, textura, posição e direção, o que incrementa a atenção dos usuários para o ambiente, e, por conseguinte, fortalece o vínculo ambiente vs. público. Ademais, adota mecanismos que podem levar a um foco sobre determinado tópico ou tema. Se assim acontecer, o contraste contribui para que se eleja parte dominante da peça e, então, os demais elementos seguem ordem hierárquica, a partir do ponto focal enfatizado.

O contraste, além de proporcionar, no primeiro instante, visão geral do todo, amplia a legibilidade do ambiente, quando atua sobre letras e em cores de fundo. Pode ser ele explicitado entre cores do fundo e a cor da letra. Tamanhos e tipos de letras diferentes são algumas das opções de contraste.

Heurísticas 4 - Legibilidade com adequada densidade de informação. Essa Heurística relaciona-se com os aspectos que intervêm na leitura, como já explorado, em detalhes. Entre eles: tamanho e tipo da fonte empregada; contraste entre fonte e fundo; impactos da imagem inserida no texto etc. Repetimos que fontes Arial são melhores para ler do que as do tipo Times New Roman, para citar como exemplo, embora ambas possam oferecer legibilidade.

De forma similar e como descrito, letras escuras em fundo claro são mais usadas do que letras claras em fundo escuro. Textos que alternam maiúsculas e minúsculas são lidos mais rapidamente do que os que se apresentam somente com letras maiúsculas. Poucas linhas mais longas ao invés de muitas linhas mais curtas também são sugeridas. Afora essas colocações, lembramos que a densidade de informação no vídeo é componente importante.

Heurísticas 5 - Consideração da experiência e compatibilidade usuário. Trata-se dos meios implementados, os quais permitem que o sistema respeite 0 nível de experiência dos diferentes sujeitos, permitindo-Ihes selecionar o nível de detalhamento das mensagens de erro, em função de seu background.

Isto significa prever atalhos, favorecendo aos experientes contornarem seleções por menu, através da especificação de comandos ou de atalhos de teclado. Significa, ainda, prever a escolha de entradas simples ou múltiplas, conforme a vivência de cada um, além de autorizar diferentes modos de diálogos 
correspondentes aos diferentes grupos de usuários e de permitir a digitação de vários comandos antes da confirmação dos mais experimentados. Este item também se refere à chance de fornecer tutorial, passo a passo, para os menos habilitados.

Heurísticas 6 - Flexibilidade e adaptação ao ambiente do usuário. Esse critério é importante, porque se refere às exigências do usuário. Como exemplo, ferramentas que possibilitam controlar e modificar a configuração das telas. Quando, em algum contexto, a validade de certas apresentações não puder ser determinada, fornecer aos indivíduos o direito de desativá-las temporariamente. Quando os valores por default não são previamente conhecidos, o sistema deve permitir que o usuário defina, altere e até suprima valores.

Além do mais, a seqüência de entrada de dados deve ser passível de modificações, a fim de se ajustar às demandas individuais. Quando o formato do texto não pode ser previsto com antecedência, deve-se proporcionar ao usuário os meios para definir e salvar os formatos que necessita, com regularidade, para seus trabalhos. Por exemplo: alinhamento à esquerda, alinhamento centralizado, número com pontos flutuantes, potencias de bases diversificadas.

Heurísticas 7 - Identificação do ambiente e orientação ao usuário. $O$ critério ora apresentado diz respeito a quão importante é a repetição de um sinal para identificar elementos de um ambiente na web. Cada parte na web deve parecer pertencer ao mesmo ambiente, à mesma empresa, para demonstrar a mesma filosofia visual e, se possível, que assuma uma identificação do que será repetido. Além de unificar o ambiente, um sistema consistente no visual explicita um padrão em cores, tamanhos e tipos de letras, facilitando para que os aprendizes obtenham o máximo do ambiente, com menos esforço.

Se os usuários são capazes de reconhecer onde estão, simplesmente verificando a página onde se encontram, sem a exigência de relembrarem todo o caminho percorrido a partir da página principal, a probabilidade de ficarem desorientados é bem menor.

Heurísticas 8 - Consistência. O critério consistência refere-se à padronização tanto quanto possível de todos os objetos, no que concerne ao formato e à denominação, de modo que a disparidade dos elementos de um AVA leva à recusa na adoção de determinados ambientes. Também alude à padronização da sintaxe dos procedimentos e à localização na tela. A falta de homogeneidade nos menus, por exemplo, alarga, consideravelmente, os tempos de 
busca. Há diferentes recursos em torno da consistência, tais como: identificação única para cada tela, sempre no mesmo lugar e no topo da tela; e os campos de busca localizados na parte superior e no centro, com tendência para o lado esquerdo da tela.

Heurísticas 9 - Documentação online . A heurística documentação online, exemplificada constitui recurso relevante num sistema, embora, em geral, os usuários se mostrem impacientes para ler e somente a consultem no caso de problemas ou de dificuldades extremas de uso. Quando o sistema mantém projeto sofisticado, é imprescindível que disponibilize documentação vasta, completa e coerente com os tipos de documentação existentes (manual ou on-line.manual do usuário, manual do sistema etc. um boa documentação deve contemplar uma adequada documentação para gestão de erros.

Heurísticas 10 - Pregnância. O princípio da pregnância figura como um dos critérios mais importantes. No mínimo, o mais sintético. Quaisquer formas podem ser percebidas em seu caráter mais simples, o que corresponde a afirmar que cada um dos componentes deve ser construído de forma simples e compreensível: para que elaborar um ícone, uma imagem ou um ambiente (como um todo), cujas partes não estão integradas e são de difícil apreensão? Por lei da pregnância entende-se uma organização psicológica que pode sempre ser tão boa quanto as condições o permitirem. É importante ressaltar que o termo "bom" permanece não definido. A pregnância contém propriedades como regularidade, simetria e simplicidade.

\section{CONCLUSÃO}

A pesquisa ora finalizada, ao priorizar, especificamente, interfaces de AVA, de certa forma, preenche lacuna existente nos estudos de interfaces computacionais, até porque, os estudos analisados, em sua maioria, apresentam recomendações genéricas como nas publicações de ergonomia de softwares de Bastien e Scapin (1992, 1993, 1995); Nielsen (1993, 2000); Scapin (1988) e Shneiderman (1998). De forma que muito pode ser construído para maximizar a usabilidade de Ambientes Virtuais de Aprendizagem (AVA).

Concluímos então, que não existe interface de AVA totalmente adequada às necessidades dos usuários desses ambientes virtuais, no entanto aplicando-se as recomendações de usabilidade aqui explicitadas é possível que tenhamos usuários 
mais satisfeitos realizando todas as funções de um AVA com menos esforço e mais rendimento, diminuindo assim a carga de trabalho.

\section{REFERÊNCIAS}

BASTIEN, J. M. C.; SCAPIN, D. L. Evaluating a user interface with ergonomic criteria. International Journal of Human-Computer Interaction, [S. I.], v. 7, n. 1, p. 105-121, 1995.

E-PROINFO. Ambiente colaborativo de aprendizagem a distância. Disponível em: http://www.eproinfo.mec.gov.br. Acesso em: 12 mar. 2018.

GUEDES, G. Avaliação Ergonômica da Interface Humano-Computador de Ambientes Virtuais de Aprendizagem (AVA). Tese de doutorado apresentada no programa de pós-graduação em Educação da Universidade Federal do Ceará em agosto de 2008.

FRANÇA-CARVALHO, A. D. Conversas pedagógicas: reflexões sobre o cotidiano da docência. Teresina, EDUFPI, 2010.

MOODLE. Modular Object-Oriented Dynamic Learning Environment.

[Informações gerais]. Disponível em: http://moodle.org/. Acesso em: 5 ago. 2008.

NIELSEN, J. Projetando websites: designing web usability. Rio de Janeiro: Campus, 2000.

SHNEIDERMAN, B. Designing the user interface. 3. ed. Massachusetts: AddisonWesley Publ., 1998. 639 p.

SILVA, C. R. de O. MAEP: um método ergopedagógico interativo de avaliação para produtos educacionais informatizados, 2002. f. Tese (Doutorado em Engenharia de produção) - Universidade Federal de Santa Catarina, Florianópolis. 2002.

SOLAR. Sistema On line de Aprendizagem. Disponível em: www.vdl.ufc.br/solar. Acesso em: 22 mar. 2018. 